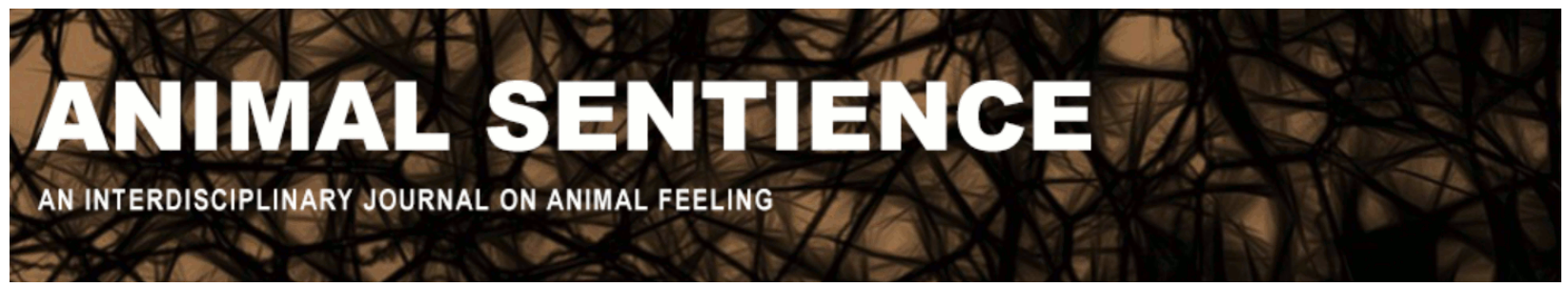

Merskin, Debra (2019) Across the great divide. Animal Sentience 23(41)

DOI: $10.51291 / 2377-7478.1410$

Date of submission: 2019-02-09

Date of acceptance: 2019-02-27

(c) (i)

This article has appeared in the journal Animal

Sentience, a peer-reviewed journal on animal

cognition and feeling. It has been made open access,

free for all, by WellBeing International and deposited

in the WBI Studies Repository. For more information,

please contact

wbisr-info@wellbeingintl.org.

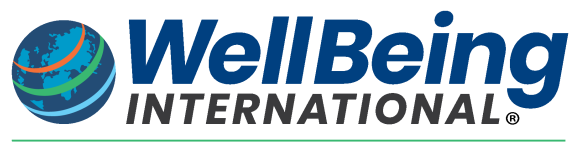

SOLUTIONS FOR PEOPLE, ANIMALS AND ENVIRONMENT 


\title{
Across the great divide
}

Commentary on Chapman \& Huffman on Human Difference

\author{
Debra Merskin \\ School of Journalism \& Communication \\ University of Oregon
}

\begin{abstract}
Chapman \& Huffman's target article calls for a reevaluation of claims of human uniqueness and superiority. It also adds to the literature on how species differences, as Darwin noted, are more of degree than kind. The threats to environmental health and species survival are a consequence of excluding nonhuman animals from moral concern and consideration. The theory of intersectionality should include speciesism in the array of discriminatory practices.
\end{abstract}

Debra Merskin, Professor of Media Studies, School of Journalism \& Communication, University of Oregon, is the author of Seeing Species: Re-presentations of Animals in Media \& Popular Culture (Peter Lang, 2018). Website

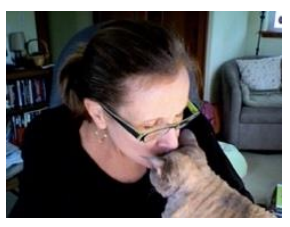

Persistent Questions. "Why do we want to think humans are different?" Chapman \& Huffman (2018) (C \& H) ask a question that authors in the humanities (Derrida, 2001; Fudge, 2002), social sciences (Bastian, Costello, \& Loughnan, 2011; Merskin, 2018; Ferdowsian \& Merskin, 2012), and sciences (Bekoff, 2006), as well as philosophers (Regan, 2010) have asked over the centuries.

In "Why do we ..." the "We" presumably refers to the "greater humanity" that insists there is a clear division between humans and nonhuman animals, even though We are also animals. This We is situated primarily in the context of Western Christian thought; an Eastern and indigenous "We" may have very different relationships with animals.

The second part of the question, “... want to think humans are different?" reflects the insistence on maintaining distinctions to justify differential treatment of nonhuman animals distinctions such as the capacity for speech, tool use, emotions, rationality, and so forth. This insistence has significant consequences for the lives of other animals.

Deeply embedded in the Western human psyche is the tendency to regard some beings as superior to others based on arbitrary criteria. Apart from what we do to other species, differential treatment has a long history within our own species. From discrimination to torture and genocide, if one group looks down on or fears another, lines are drawn and distinctions are made. Classification results in prejudices and stereotypes about humans classified as "others" (Bastain, Costello, Loughnan, \& Hodson, 2011; Merskin, 2011, 2018; Plous, 2003). Anti-immigrant discourse in the United States is a contemporary example.

$\mathrm{C} \& \mathrm{H}$ ask a second longstanding question: " $[\mathrm{H}]$ as the false sense of superiority been used to justify human cruelty to animals?" The answer is, of course, a resounding "Yes!" for anyone who has thought about animals as "subjects-of-a-life" (Regan, 2010, p. 161) rather than as 
research objects, hunting targets, food, or entertainment. The absence of any real superiority has been proven in multiple ways. Tool use was once used to maintain difference. Today we know that elephants, crows, some fish, sea otters, and many corvids use them for a variety of purposes. Osler's (1891) claim that it was "a desire to take medicine" that distinguished humans from other animals has also been proven false, $\mathrm{C} \& \mathrm{H}$ note, because we now know that many mammals (coatis, civets, bears, and elephants) as well as some birds (raptors, finches) and insects (butterflies, bees, and ants) seek and use various substances to cure or ease what ails them. Abstract thought, such as that required to build structures, has also been used to claim superiority, yet many birds and insects build highly complex homes.

The costs of an inflated sense of importance and superiority are illustrated in the target article by the loss of biodiversity and species; however, what is under-emphasized is the "more than nine billion animals [who are] raised and slaughtered for human consumption each year in the U.S. alone" (Farm Sanctuary). Greenhouse gas emissions from factory farming that include the release of methane, water and ground pollution, and other pollutants may be an even bigger contributor to climate change than oil production (Gerber, Steinfeld, Henderson, Mottet, Opio, Dijkman, Falcucci, \& Tempio, 2013).

Regarding C \& H's second question about cruelty: the physical and psychological suffering of animals raised for food (and fur and research, some with little or no protection from federal organizations such as the USDA) is profound (Freeman, 2014). Disregard and cruelty are natural effects of objectification because the more nonhuman animals are like us, the more willing we are to grant them rights and protections. Hence dissimilarities must be maintained if We are to continue treating them as We do. The multi-billion-dollar dairy, beef, and pork industries work hard to conceal the similarities, as well as the suffering.

According to Costello \& Hodson's (2010) Interspecies Model of Prejudice, "devaluing animals provides the fuel for devaluing other humans" (Hodson, 2012). According to Crenshaw's (2010) theory of "intersectionality," markers of difference such as sex, gender, and race need to be considered collectively in order to understand discrimination. Speciesism should be added to Crenshaw's three markers if we are to understand the complex dynamics of human prejudices toward some humans and nearly all animals.

The deep connection between human and animal enslavement and suffering is what Spiegel (1988) called "the dreaded comparison." The analogy has always been considered ethically controversial - again because nonhuman animals are given the lowest status. It is especially painful for someone from a human group who has been the victim of discrimination. Yet Plous (2003, p. 510) has pointed out that "[t]he very act of 'treating people like animals' would lose its meaning if animals were treated well." To invoke prejudice and intersectionality to discuss the mistreatment of animals is not to say we are the same, but that exceptionalism and discrimination have psychological similarities. Increased moral inclusiveness comes when animals are recognized as being more like Us.

The questions C \& H ask are not new. They are old and often repeated. That is precisely why their article is important. We need to keep asking $C \& \mathrm{H}^{\prime}$ s questions until changes are made in the treatment of nonhuman animals. 


\section{References}

Bastain, B., Costello, K., Loughnan, S., \& Hodson, G. (2011). When closing the human-animal divide expands moral concern: The importance of framing. Social Psychological and Personality Science, 1(9): 1-9.

Bekoff, M. (2006). Animal passions and beastly virtues: Cognitive ethology as the unifying science for understanding the subjective, emotional, empathic, and moral lives of animals. Human Ecology Review, 13(1): 39-59.

Chapman, C. A., \& Huffman, M. A. (2018). Why do we want to think humans are different? Animal Sentience 23(1).

Costello, K., \& Hodson, G. (2010). Exploring the roots of dehumanization: The role of animalhuman similarity in promoting immigrant humanization. Group Processes and Intergroup Relations, 13: 3-22.

Crenshaw, K. W. (2010). Close encounters of three kinds: On teaching dominance feminism and intersectionality. Tulsa Law Review, 46: 151.

Derrida, J. (2002). The animal that therefore I am. NY: Fordham University Press.

Farm Sanctuary. (n.d.). Factory farming and the environment.

Ferdowsian, H., \& Merskin, D. (2012). Parallels in sources of trauma, pain, distress, and suffering in humans and nonhuman animals. Journal of Trauma \& Dissociation, 13(4): 448-468.

Freeman, C. P. (2014). Framing farming: Communication strategies for animal rights. NY: Brill. Fudge, E. (2004). Animal. London: Reaktion Books.

Gerber, P. J., Steinfeld, H., Henderson, B., Mottet, A., Opio, C., Dijkman, J., Falcucci, A., \& Tempio, G. (2013). Tackling climate change through livestock - A global assessment of emissions and mitigation opportunities. Food and Agriculture Organization of the United Nations (FAO), Rome.

Hodson, G. (2012, June 19). The human-animal divide and prejudices against humans. Psychology Today.

Merskin, D. (2011). Media, minorities, and meaning: A critical introduction. NY: Peter Lang.

Merskin, D. (2018). Seeing species: Re-presentations of animals in media and popular culture. NY: Peter Lang.

Osler, W. (1891). Recent advances in medicine. Science 17: 170-171.

Plous, S. (2003). Is there such a thing as prejudice toward animals? In S. Plous (Ed.), Understanding prejudice and discrimination (pp. 509-528). NY: McGraw Hill.

Regan, T. (2010). Animals as subjects-of-a-life. In D. R. Keller (Ed.), Environmental ethics: The big questions (pp. 161-168). NY: Wiley-Blackwell.

Spiegel, M. (1988). The dreaded comparison: Human and animal slavery. NY: Mirror. 